\title{
Survival of Campylobacter jejuni in chicken meat, chicken skin and chicken liver at low temperatures
}

\author{
Kocic B ${ }^{1}$, Ivic-Kolevska $\mathrm{S}^{2}$, Miljkovic-Selimovic B ${ }^{1}$, Milosevic $\mathrm{Z}^{1}$ \\ Institute for Public Health, Nis, Serbia. kocicb@yahoo.com
}

\begin{abstract}
The aim of this study was to determine survival of Campylobacter jejuni (C. jejuni) in chicken meat, chicken skin medallions and chicken liver contaminated with this bacterium at $+4{ }^{\circ} \mathrm{C}$ and $-20^{\circ} \mathrm{C}$, after 24 hours of incubation. The survival of $\mathrm{C}$. jejuni at $+4{ }^{\circ} \mathrm{C},-20^{\circ} \mathrm{C}$ in chicken meat, chicken skin medallions and chicken liver were examined after 24 hours of incubation with $C$. jejuni. All samples were previously tested for the presence of Campylobacter species according to ISO 10272-1:2006. After 24 hours of incubation at $+4{ }^{\circ} \mathrm{C}$, the number of survived $C$. jejuni in chicken meat slightly decreased on both non-selective and selective plates, but still in range of $10^{6}$. After 24 hours of incubation at $-20^{\circ} \mathrm{C}$, the number of survived $\mathrm{C}$. jejuni in chicken meat was in range of $10^{6} \mathrm{cfu} / \mathrm{ml}$ on non-selective plate, with complete absence of growth on selective plate. After 24 hours of incubation, the number of survived $C$. jejuni in chicken liver increased on selective and non-selective plates $\left(>10^{7}\right)$ at $+4{ }^{\circ} \mathrm{C}$, while at $-20{ }^{\circ} \mathrm{C}$ there were no $\mathrm{C}$. jejuni survived on both plates. 24 hours of incubation at both temperatures did not much influence the number of $C$. jejuni in chicken meet, while chicken skin medaillons allowed increase of the number of bacteria. Incubation of chicken liver at $+4^{\circ} \mathrm{C}$ allowed bacterial multiplication, while incubation at $-20^{\circ} \mathrm{C}$ caused absence of survival (Tab. 1, Ref. 12). Full Text in PDF www.elis.sk.

Key words: Campylobacter jejuni, chicken meat, chicken skin, chicken liver.
\end{abstract}

Enteric infections caused by Campylobacter are the most frequently reported zoonoses in humans in the EU with an incidence rate of approximately 50 confirmed cases per 100.000 inhabitants over 17 countries (EFSA, 2009). The majority of cases of campylobacteriosis are self-limiting with 3-5 days of acute diarrhea, abdominal pain and fever. However, disease in the very young and elderly can be serious and sequelae of infection, such as polyneuropathies, may result in the need for hospitalization. Thus, the public health and social consequences of campylobacteriosis are significant for the EU.

Campylobacter can colonize the intestinal tracts of birds at high levels and faecal contamination of poultry carcasses can occur during processing. One of the principal routes of human exposure is considered to be cross-contamination from poultry meat during food preparation in kitchens. Control of Campylobacter in poultry meat is a major public health strategy for the prevention of campylobacteriosis (Otasevic et al, 2004).

The bacteria can readily contaminate various foodstuffs, including meat, raw milk and dairy products and less frequently, fish and fishery products, mussels and fresh vegetables. Among sporadic cases, contact with live poultry, consumption of poultry meat, drinking water from untreated water sources and contact with pets and other animals have been identified as the major sources of infection. Raw milk and contaminated drinking water have been incriminated in large outbreaks (EFSA, 2007).

${ }^{1}$ Institute for Public Health, Nis, Serbia, and ${ }^{2}$ Institute of Public Health, Skopje, Macedonia

Address for correspondence: B. Kocic, MD, Institute for Public Health, School of Medicine, Bul. Dr Z. Djindjica 50, 18000 Nis, Serbia.

\section{Aim}

To determine survival of Campylobacter jejuni (C. jejuni) in chicken meat, chicken skin medallions and chicken liver contaminated with this bacterium at $+4{ }^{\circ} \mathrm{C}$ and $-20^{\circ} \mathrm{C}$, after 24 hours of incubation.

\section{Materials and methods}

Examinations were performed in the National Referent Laboratory for Campylobacter and Helicobacter-Center of Microbiology, Institute for Public Health, in Nis, Serbia. The survival of $C$. jejuni at $+4{ }^{\circ} \mathrm{C},-20^{\circ} \mathrm{C}$ in chicken meat, chicken skin medallions and chicken liver were examined after 24 hours of incubation with C. jejuni isolated from human faeces. Also, we determined the number of bacteria in inoculated samples 30 minutes after inoculation, at room temperature $\left(25^{\circ} \mathrm{C}\right)$.

All samples were purchased at a local retail market and were stored fresh at $+4{ }^{\circ} \mathrm{C}$ for maximum 1 day and were previously tested for the presence of Campylobacter species according to ISO 10272-1:2006 and ISO 10272-2:2006. Only specimens, which did not contain Campylobacter species, were processed. That is why there was no need for decontamination of Campylobacter spp. in examined food samples of chicken meat, chicken skin medallions and chicken liver.

This study included the following samples: $10 \mathrm{~g}$ of chicken meat, $10 \mathrm{~g}$ of chicken liver and $2.5 \mathrm{~g}$ of chicken skin (measured on digital balance, SCALTEC, Germany). All samples were placed in bags (Becton Dickinson, NJ, USA) with addition of three different strains mixture of $C$. jejuni suspension with the final concentra- 
Tab. 1. Survival of $C$. jejuni at $+4^{\circ} \mathrm{C}$ and $-20^{\circ} \mathrm{C}$ in chicken meat, chicken skin and chicken liver.

\begin{tabular}{|c|c|c|c|c|}
\hline \multirow[t]{2}{*}{ Type of material } & \multirow[t]{2}{*}{ Plate } & \multirow{2}{*}{$\begin{array}{c}\mathrm{CFU} / \mathrm{ml} \text { after } 30 \text { min of incubation } \\
\text { at room temperature }\end{array}$} & \multicolumn{2}{|c|}{$\mathrm{CFU} / \mathrm{ml}$ after 24 hours of incubation } \\
\hline & & & $+4^{\circ} \mathrm{C}$ & $-20^{\circ} \mathrm{C}$ \\
\hline \multirow[t]{2}{*}{ Chicken meat } & Non-selective & $3 \times 10^{6}$ & $2.4 \times 10^{6}$ & $0.3 \times 10^{6}$ \\
\hline & Selective & 0 & $1,5 \times 10^{6}$ & 0 \\
\hline \multirow[t]{2}{*}{ Chicken liver } & Non-selective & $1.2 \times 10^{6}$ & $>10^{7}$ & 0 \\
\hline & Selective & 0 & $>10^{7}$ & 0 \\
\hline \multirow[t]{2}{*}{ Chicken skin } & Non-selective & $2 \times 10^{6}$ & $3.1 \times 10^{7}$ & $2.9 \times 10^{7}$ \\
\hline & Selective & 0 & $7.4 \times 10^{7}$ & $3.3 \times 10^{7}$ \\
\hline
\end{tabular}

tion of approximately $10^{8} \mathrm{CFU} / \mathrm{g}(800 \mu \mathrm{l} / \mathrm{g}$ for chicken meat and chicken liver, and $200 \mu \mathrm{l} / \mathrm{g}$ for chicken skin samples). After removing the excess of air, the whole amount of the inoculums with sample were stored in closed bags, to prevent drying.

After the incubation period ( 24 hours), every sample incubated at $+4{ }^{\circ} \mathrm{C}$ and $-20{ }^{\circ} \mathrm{C}$ was left to defrost spontaneously. Samples were diluted $1: 10$ in $0,85 \%$ of sodium chloride based on the previously determined weight and pummeled for 2 min using a Stomacher 400 lab blender (MIX2, $\Lambda$ ES Laboratorie, Seward, London, UK). The $0,1 \mathrm{ml}$ homogenate, serially diluted in $0.85 \%$ of sodium chloride were cultivated in duplicate, on both selective (Campylobacter agar (sheep blood $5 \%$ ) Liofilchem, Italy) and non-selective media (Columbia agar (sheep blood $5 \%$ ) Liofilchem, Italy) for campylobacter isolation. Plates were incubated at $37^{\circ} \mathrm{C}$ for $48 \mathrm{~h}$ in microaerobic atmosphere (Becton Dickinson, NJ, USA). Thereafter, the growth of $C$. jejuni was confirmed based on typical colony and bacterial cells morphology, standard biochemical tests and API Campy identification system (bioMerieux, France).

\section{Results}

After 30 minutes of incubation at room temperature $\left(25^{\circ} \mathrm{C}\right)$, the number of survived $C$. jejuni decreased on the non-selective plate from $10^{8} \mathrm{CFU} / \mathrm{ml}$ to $3 \times 10^{6} \mathrm{CFU} / \mathrm{ml}, 1.2 \times 10^{6} \mathrm{CFU} / \mathrm{ml}$ and $2 \times 10^{6} \mathrm{cfu} / \mathrm{ml}$, in chicken meat, chicken skin and chicken liver, respectively. There was no growth on selective plate for all three types of samples (Tab. 1).

After 24 hours of incubation at $+4{ }^{\circ} \mathrm{C}$, the number of survived C. jejuni in chicken meat slightly decreased on both non-selective and selective plates, but still in range of $10^{6}$. After 24 hours of incubation at $-20^{\circ} \mathrm{C}$, the number of survived C. jejuni in chicken meat was in range of $10^{6} \mathrm{cfu} / \mathrm{ml}$ on nonselective plate, with a complete absence of growth on selective plate (Tab. 1).

After 24 hours of incubation, the number of survived $C$. jejuni in chicken liver increased on selective and non-selective plates $\left(>10^{7}\right)$ at $+4{ }^{\circ} \mathrm{C}$, while at $-20^{\circ} \mathrm{C}$ there were no $C$. jejuni survived on both plates (Tab. 1).

The number of survived C. jejuni after 24 hours of incubation in chicken skin increased at both temperatures $\left(+4{ }^{\circ} \mathrm{C}\right.$ and $\left.-20^{\circ} \mathrm{C}\right)$ on selective and non-selective plates $\left(>10^{7}\right)$ (Tab. 1).

\section{Discussion}

In 2007, campylobacteriosis was the most frequently reported zoonotic disease in humans in the European Union with 200,507 reported confirmed cases and most EU Member States reported an increased number of cases (EFSA, 2009).

Campylobacter is especially sensitive to freezing, although there appears to be some variation in the freezing tolerance between C. jejuni strains (Archer, 2004; Taylor et al, 2005). The freezing of carcasses from poultry flocks that test positive for Campylobacter is mandatory in some countries and has been shown to reduce the risk of campylocterioses (Archer, 2004; Thurston et al, 2003).

Thirty minutes of incubation of inoculated material during samples processing at room temperature $\left(25^{\circ} \mathrm{C}\right)$ decreased the number of survived C. jejuni from $10^{8} \mathrm{CFU} / \mathrm{ml}$ to $10^{6} \mathrm{cfu} / \mathrm{ml}$ indicating a decrease of bacteria in inoculum. Absence of growth on selective plates implied a sublethal injury of the cells.

In this trial, the incubation of 24 hours at $+4{ }^{\circ} \mathrm{C}$ and $-20^{\circ} \mathrm{C}$ did not affect the survival of $C$. jejuni in chicken meat. Many studies have demonstrated that freezing and frozen storage reduce the survival of Campylobacter in meat. Zhao et al (2003) inoculated three isolates of $C$. jejuni on to chicken wings, which were frozen at $-20{ }^{\circ} \mathrm{C}$ or $-30{ }^{\circ} \mathrm{C}$ for 72 hours. Freezing chicken at $-20{ }^{\circ} \mathrm{C}$ and $-30{ }^{\circ} \mathrm{C}$ for 30 minutes had a minimal effect on C. jejuni survival, but over 72 hours both treatments reduced the number of $C$. jejuni recovered (Zhao et al, 2003).

After 24 hours incubation at $+4{ }^{\circ} \mathrm{C}$ in this study, there was an increase of the number of $C$. jejuni in chicken liver while at -20 ${ }^{\circ} \mathrm{C}$ no C. jejuni survived. This indicates that the temperature of +4 ${ }^{\circ} \mathrm{C}$ may be favorable environmental condition for development of C. jejuni in chicken liver. In available literature, there were no data related to the survival of $C$. jejuni in chicken liver.

This study showed an increase in the number of $C$. jejuni after 24 hours of incubation at both temperatures $\left(+4{ }^{\circ} \mathrm{C}\right.$ and $\left.-20{ }^{\circ} \mathrm{C}\right)$ on chicken skin. In three trials (different storage conditions and different temperature), higher populations of $C$. jejuni were found on skin vs. meat on all sample days (1 day, 9, 11 days) (David and Connert, 2007). On contrary, in other investigation whatever the enumeration method was used during the first two weeks after contamination with bacterium inoculum, the inactivation seems to be the larger on skin than below the skin and the least on the muscle (Ritz-Bricaud et al, 2007).

Since different results have been obtained in different researches, further investigations are needed to clarify the influence of low temperatures to the survival of Campylobacter jejuni in chicken meat and especially chicken skin and chicken liver.

According the referred studies, the long-term freezing of Campylobacter spp. at low temperatures (preferable on $-20^{\circ} \mathrm{C}$ for 8 to 10 weeks) in specified type of chicken meat, liver and skin, will 


\section{4-356}

significantly reduce the possibility of survival of Campylobacter spp. and development of infections (David and Connert, 2007; Taylor et al, 2005; Zhao et al, 2003).

To analyze the conditions of survival of Campylobacter spp. and its microbiological susceptibility should be of great importance in daily managing with mentioned chicken products, in order to reduce the possibility of cross-contamination and to prevent development of campylobacteriosis, which is the most frequent cause of foodborn disease.

Ensuring the absence of $C$. jejuni through hygienic practice, or as a less desirable option, through decontamination technologies, would represent the best way to obtain safe food, including meat and meat products (Moorrhead and Dykes, 2002).

\section{Conclusion}

Incubation of all samples at the room temperature during processing decreased the start amount of bacteria in the inoculum, especially on selective plate where the growth was completely absent for all types of samples. 24 hours of incubation at both temperatures did not much influence the number of $C$. jejuni in chicken meet. Surprisingly, incubation of chicken liver at +4 ${ }^{\circ} \mathrm{C}$ allowed bacterial multiplication, while incubation at $-20{ }^{\circ} \mathrm{C}$ caused an absence of survival. 24 hours of incubation of chicken skin medaillons allowed an increase of the number of bacteria on both temperatures. Further investigations are needed to clarify the influence of low temperatures to the survival of $C$. jejuni in chicken meat, chicken skin and chicken liver.

\section{References}

1. Archer DL. Freezing: an underutilized food safety technology? Int J Food Microbiol 2004; 90: 127-138.

2. Davis MA, Connert DE. Survival of Campylobacter jejuni on poultry skin and meat at varying temperatures. Poult Sci 2007; 86 (4): 765-767.

3. European Food Safety Authority. The Community Summary Report on trends and sources of zoonosis, zoonotic agents, antimicrobial resistance and food borne outbreaks in the European Union in 2005. The EFSA J 2007; 18: 84-103.

4. European Food Safety Authority. The Community Summery Report on Trends and Sources of Zoonoses and zoonotic Agents in the European Union in 2007. The EFSA J 2009: 223.

5. ISO 10272 -1: Microbiology of food and animal feeding stuffs - Horizontal method for detection and enumeration of Campylobacter spp. - Part 1: Detection method, 2006.

6. ISO 10272 -2: Microbiology of food and animal feeding stuffs - Horizontal method for detection and enumeration of Campylobacter spp. - Part 2: Colony-count technique, 2006.

7. Moorhead SM, and Dykes GA. Survival of Campylobacter jejuni on beef trimmings during freezing and frozen storage. Lett Appl Microbiol $2002 ; 34: 72-76$.

8. Otasevic M, Lazarevic-Jovanovic B, Dimov-Tasic D, Djordjevic N, Miljkovic-Selimovic B. Ucesce pojedinih vrsta kampilobaktera u etiologiji enterokolitisa. Vojnosanit Pregl 2004; 61 (1): 21-27.

9. Ritz-Bricaud M, Nauta MJ, Teunis PFM, Federighi M, Havelaar AH. Modelling of Campylobacter survival on frozen chicken meat. J Appl Microbiol 2007; 103 (3): 594-600.

10. Taylor K, Whyte R, Wong T. Effect of low temperature on Campylobacter on poultry meat. Food Safety Programme, 2005: 4-33.

11. Thurston SB, Cloak OM, Fratamico PM. Effect of temperature on viability of Campylobacter jejuni and Campylobacter coli on raw chicken or pork skin. J Food Prot 2003; 66: 2023-2031.

12. Zhao T, Ezeike GO, Doyle MP, Hung YC, Howell RS. Reduction of Campylobacter jejuni on Poultry by Low-Temperature Treatment. J Food Prot 2003; 66 (4): 652-655. 